\title{
Association between occupational exposure and Dupuytren's contracture using a job- exposure matrix and self-reported exposure in the CONSTANCES cohort
}

Marc Fadel $^{1,2}$, Annette Leclerc ${ }^{2}$, Bradley A Evanoff ${ }^{3}$, Ann-Marie Dale ${ }^{3}$, Laure Ngabirano ${ }^{4}$, Yves Roquelaure ${ }^{4}$, Alexis Descatha ${ }^{1,2,4}$

1. AP-HP, UVSQ, IIMTPIF, Unité Hospitalo-Universitaire de Santé professionnelle Hôpitaux Universitaires de Paris Ile-de-France Ouest, site Raymond Poincaré, Garches, France

2. Versailles St-Quentin Univ UVSQ, Paris Sud Univ, Paris Saclay Univ, Inserm, U1168 (VIMA: Aging and chronic diseases. Epidemiological and public health approaches), UMS 011 (Population-based Epidemiologic Cohorts Unit), Villejuif, France

3. Division of General Medical Sciences, Washington University School of Medicine in St. Louis, St. Louis, Missouri, USA

4. Univ Angers, CHU Angers, Univ Rennes, Inserm, EHESP, Irset (Institut de recherche en santé, environnement et travail) - UMR_S1085, Angers, France

Corresponding author: Dr Marc Fadel, Unité hospitalo-universitaire de santé professionnelle, CHU Poincaré, 104 bd Poincaré, 92380 Garches, France Tel: +33 (1) 471077 64; Fax: +33 (1) 471077 68; email: marc.fadel@ens.uvsq.fr Word Count: 1498 


\begin{abstract}
Background: Although several studies highlighted an association between occupational exposure and Dupuytren's contracture (DC), they were often limited by the highly selected population. We aimed to study this association using a job-exposure matrix (JEM) and selfreported exposure in a large cohort.
\end{abstract}

Methods: From CONSTANCES, a French population-based prospective cohort, we retrieved sex, age, social position, alcohol/tobacco intake and diabetes. Lifetime exposures were assessed by two different methods: with the biomechanical JEM "JEM Constances", we assessed exposure to vibration and/or forearm rotation for participants whose work history was available, and from a self-administered questionnaire, we retrieved self-reported exposure to arduous work and/or carrying heavy loads. Surgery for DC was collected from the French Health Administrative database from 2009 to 2016. Multivariate logistic regression models adjusted for confounders were built to assess association between surgery for DC and occupational exposures.

Results: Work history was retrieved for 23,795 subjects among whom 98 underwent surgery for DC. Adjusted odds ratio (aOR) was of 2.08 (1.03-4.2) for being ever exposed to vibration and/or forearm rotation for subjects $<60$ years and of $1.20(0.69-2.08)$ for subjects $\geq 60$ years. Data for self-reported exposure were available for 81,801 participants among whom 367 underwent surgery for DC. aOR for being exposed more than 20 years to arduous work and/or carrying heavy loads was of $2.01(1.32-3.04)$ for subjects $<60$ years and of $1.04(0.7-1.54)$ for subjects $\geq 60$.

Conclusions: Manual work is associated with surgery for DC among younger subjects. Monitoring exposed workers is important to prevent future functional limitations. 
Keywords: Dupuytren's contracture, occupational, job-exposure matrix, epidemiology

Key messages

What is already known about this subject?

- Work exposures to vibration and manual work have been suggested as risk factors for Dupuytren's contracture.

- Existing studies were often limited by the selected population and the assessment of confounders.

What are the new findings?

- Exposure to vibration and/or forearm rotation assessed by a job-exposure matrix was associated with Dupuytren's contracture, as was self-reported exposure to arduous work and/or carrying heavy loads.

How might this impact on policy or clinical practice in the foreseeable future?

- Exposed workers should be informed and monitored to allow early detection and treatment in order to prevent possible functional limitation. 


\section{INTRODUCTION}

Dupuytren's contracture (DC) is a hyperproliferative disease affecting the hand, characterized by nodule formations in the early stages and the appearance of ropelike growth called "cords" later on which can cause flexion contractures of the fingers.[1] Prevalence of DC treated or diagnosed is estimated around $1 \%$ in France and the United-States[2,3] but may vary between countries. Deformities in DC can lead to physical limitations and are associated with major direct and indirect cost due to surgery or lost work days.[4] Several studies have highlighted an association between occupational exposures to manual work or vibration and DC.

However, they were often limited by the highly selected population and the lack of adjustment for confounding factors.[5] Assessing past work exposures is challenging since direct observation of workers is time intensive and can only measure current work. Recently developed job exposure matrices (JEMs) allow estimation of past exposures in general populations.[6] To our knowledge, this is the first article that uses a JEM to assess work exposure for DC.

This study aims to describe the association between biomechanical exposures during working life and surgery for DC, while considering potential confounders in a large cohort. Lifetime work exposure will be assessed by a JEM and by individual self-reports.

\section{METHODS}

\section{Population}

CONSTANCES is a population-based prospective cohort created in 2012 to follow 200,000 volunteers between 18 to 69 years of age who are covered by the French National Health Insurance (CNAM) in France. The cohort's design and establishment are detailed 
elsewhere.[7] Variables of interest were collected from the baseline self-administered questionnaire and medical interview.

Surgery for DC, including palmar or digital fasciotomy and percutaneous needle fasciotomy, was retrieved between 2009 and 2016 from the SNIIRAM, the National Health Administrative database that gathers all compensation data for all residents in France who are affiliated to the CNAM (more than $80 \%$ of the French population). Only one surgery per participant was considered if several surgeries occurred during the period considered.

We included all participants whose job history was available at the time of the analysis. Participants who reported years of work only after 2004 (i.e. 5 years before the first case of surgery for DC) were excluded.

\section{Variables of interest}

Participants' sex, age at inception, smoking habits, alcohol intake, and socioprofessional categories (current or highest level if unemployed at the time of questionnaire) were retrieved from the baseline questionnaire, and diabetes mellitus status from the medical interview. Variables were divided as follows: age of $<60$ and $\geq 60$ years (close to age of retirement in France); non-smokers ( $=0$ pack-years), moderate smokers ( $<30$ and $>0$ pack-years) and heavy smokers ( $\geq 30$ pack-years); moderate alcohol drinkers ( $\leq 2$ drinks per day) and heavy drinkers (>2 drinks per day); and four socioprofessional categories: salaried employees, executives and managers, intermediate professions, and manual workers.

JEM Constances, which is based on self-reported exposure grouped by job titles,[8] was used to evaluate occupational exposure to vibration and forearm rotation. In the JEM, occupational exposure is rated from 0 (never or almost never exposed) to 3 (almost always exposed) for forearm rotation and for usage of vibrating tools ("vibrations") based on reported job titles. Forearm rotation was used as a proxy for strenuous work with the hand. Using the 
participants' job history data, a lifetime exposure JEM score was calculated as the sum of the number of years worked in each job, times the rating given by the JEM for each of these jobs. To ensure exposure would precede surgery for DC, exposures were included up until 5 years before the first case of DC for all participants. The 5-year lag was used a priori (based on a study reporting that the average time from the first symptoms to surgery was of 28.2 months (SE 15.2)[3]) to ensure that exposure assessment would not be affected by functional limitation caused by the disease. Participants were divided in two groups: not exposed to vibration and/or forearm rotation $($ score $=0)$ and exposed (score $>0$ ).

A second analysis on a larger sample considered self-reported exposures. Participants reported if they were exposed to arduous work or carrying heavy loads and for how long during their working life. A lifetime exposure self-reported score was created based on the duration of exposure and divided as follows: no exposure to arduous work and/or carrying heavy loads, exposure $>0$ and $<10$ years, $\geq 10$ and $<20$ years, and $\geq 20$ years.

The main outcome was surgery for DC.

\section{Statistical Analysis}

Descriptive statistics were expressed as percentages. Multivariate logistic regression models were used to assess the association between surgery for DC and exposure variables. They were adjusted for age, sex, tobacco and alcohol intake and diabetes, which are known risk factors for DC. Additional analyses included models estimated in each age subgroup. A pvalue threshold of 0.05 was considered. Statistical analyses were performed using R (Version 3.5.2, packages "tidyverse, compareGroups, epiDisplay").

\section{RESULTS}


Among the 23,795 participants who had available job history and who had worked before the 5-year lag, 98 underwent surgery for DC. The average age was 52.6. Those receiving surgery for DC were older $(62.2 \% \geq 60$ years $)$ than those not receiving surgery $29.5 \% \geq 60$ years).

Self-reported exposures were available for 81,801 subjects among whom 367 underwent surgery for DC. Likewise, participants were older in the surgery group (205 (55.9\%) $\geq 60$ years versus $19,436(23.9 \%)$ in the no surgery group). In both analysis, there were more manual workers in the surgery group, and fewer managers/executives, than in the no surgery group (Supplementary Table). Differences between subjects in the cohort who had job histories available and those who did not were small $(<2 \%)$. There were fewer than $3 \%$ missing data for each variable except for socioprofessional categories $(6.6 \%)$ and selfreported exposure $(5.8 \%)$. There was no statistical difference in percentage of surgery for DC for participants with and without missing data.

In the multivariable analysis (Table1), lifetime JEM assessed exposure to vibration and/or forearm rotation was not associated with surgery for DC in the whole group: adjusted odds ratio (aOR) $1.48(0.96-2.27)$. However, the aOR was significant in the <60 subgroup: aOR 2.08 (1.03-4.2). Lifetime self-reported exposure to arduous work and/or carrying heavy loads was associated with surgery for DC: aOR 1.41 (1.06-1.87) for more than 20 years of exposure. This association was significant (global p-value $=0.004)$ and was stronger in the <60 subgroup: aOR $2.01(1.32-3.04)$.

\section{DISCUSSION}

This study found that two different kinds of work exposure (exposure to vibration and/or forearm rotation and to arduous work and/or carrying heavy loads) were significantly associated with surgery for Dupuytren's contracture among younger subjects $(<60)$ when 
taking into account confounders. The strength of the associations found is also consistent with recent studies that used different methodological approaches.[9,10]. These results support a relationship between manual work and DC with clinically significant contractures.

There are several limitations to this study. First, the study outcome was surgery for DC; since the majority of people with DC do not undergo surgery, they were not detected in this study. Also, the analyses in the $\geq 60$ subgroup may lack statistical power since surgeries for DC prior to 2009 could not be retrieved. Second, JEMs are based on job titles and thus, crudely reflect the actual exposure which can vary from one person to another within the same job title. However, JEMs are well suited for the assessment of past exposures, which cannot be captured by direct observation and are subject to recall bias. Lastly, even though there is a genetic component to DC,[11] family history could not be retrieved in this study. Nevertheless, this should not be a differential bias since it is unlikely that are more familial DC in the exposed group than in the non-exposed group.

The main strength of the study is the exposure assessment. Previous studies often lacked exposure evaluation and were limited by the selected population.[5]. In this large population based cohort, exposure was evaluated by two different methods which found similar results, supporting a robust exposure outcome relationship even though these results are not directly comparable. Indeed, even if the self-reported exposure variables may not be directly related to DC, they could be considered as a proxy for manual work. Combining a JEM with the participants' job history allows consideration of past exposures without risk of recall bias. Studies suggested that DC's possible association with occupational exposure is mainly due to chronic exposures, which are more difficult to estimate than current exposures.[2] Here, both exposure methods assessed lifetime work history. Using surgery for DC as the outcome gives high specificity, though reducing the number of cases available for study. 
Some studies suggest that early diagnosis and treatment of DC could prevent development of deformities.[12] Patients with high risk of DC, especially those with heavy occupational exposure, might benefit from early detection and possibly forestall the appearance of contractures. In this way, the occupational risks related to development of Dupuytren's contracture could be mitigated.

To conclude, this study found that chronic occupational exposures related to manual work were associated with surgery for Dupuytren's contracture among younger workers.

\section{COMPETING INTEREST}

None. ICMJE disclosure form completed.

\section{FUNDING}

The study was founded by the "Interuniversity Institution of Occupational health of Paris Ilede-France" (IIMTPIF) which had no role in the collection of data, analyses and the writing of the manuscript. The CONSTANCES Cohort Study was supported and funded by the Caisse nationale d'assurance maladie (CNAM); it is an "Infrastructure nationale en Biologie et Santé" and benefits from ANR (ANR-11-INBS-0002) grant funding. CONSTANCES is also partly funded by MSD, AstraZeneca and Lundbeck.

\section{DATA SHARING}

The data of the CONSTANCES cohort are protected by our national regulatory agency (“Commission nationale de l'informatique et des libertés", n910486). However, the CONSTANCES cohort is "an open epidemiological laboratory" and access to study protocols and data is available on request (http://www.constances.fr/conduct-project-ongoing.php).

\section{ETHICS}


All study participants gave informed consent prior to enrolling in the study. CONSTANCES has obtained authorization from the French National Data Protection Authority and was approved by the National Council for Statistical Information, the National Medical Council, and the Institutional Review Board of the National Institute for Medical Research (INSERM). (Commission nationale de l'informatique et des libertés" $n^{\circ}$ 910486, "Comité consultatif sur le traitement de l'information en matière de recherche $\left.n^{\circ} 10.628\right)$.

\section{REFERENCES}

1 Hughes TB Jr, Mechrefe A, Littler JW, et al. Dupuytren's disease. J Hand Surg 2003;3:27-40. doi:10.1053/jssh.2003.50005

2 Descatha A, Bodin J, Ha C, et al. Heavy manual work, exposure to vibration and Dupuytren's disease? Results of a surveillance program for musculoskeletal disorders. Occup Environ Med 2012;69:296-9. doi:10.1136/oemed-2011-100319

3 Dibenedetti DB, Nguyen D, Zografos L, et al. Prevalence, incidence, and treatments of Dupuytren's disease in the United States: results from a population-based study. Hand $N$ Y N 2011;6:149-58. doi:10.1007/s11552-010-9306-4

4 Macaulay D, Ivanova J, Birnbaum H, et al. Direct and indirect costs associated with Dupuytren's contracture. J Med Econ 2012;15:664-71. doi:10.3111/13696998.2012.670678

5 Descatha A, Jauffret P, Chastang J-F, et al. Should we consider Dupuytren's contracture as work-related? A review and meta-analysis of an old debate. BMC Musculoskelet Disord 2011;12:96. doi:10.1186/1471-2474-12-96

6 Cifuentes M, Boyer J, Lombardi DA, et al. Use of O*NET as a job exposure matrix: A literature review. Am J Ind Med 2010;53:898-914. doi:10.1002/ajim.20846

7 Goldberg M, Carton M, Descatha A, et al. CONSTANCES: a general prospective population-based cohort for occupational and environmental epidemiology: cohort profile. Occup Environ Med 2017;74:66-71. doi:10.1136/oemed-2016-103678

8 Evanoff BA, Yung M, Buckner-Petty S, et al. The CONSTANCES job exposure matrix based on self-reported exposure to physical risk factors: development and evaluation. Occup Environ Med Published Online First: 31 January 2019. doi:10.1136/oemed-2018105287

9 Haines A, Levis C, Goldsmith CH, et al. Dupuytren's contracture and handwork: A casecontrol study. Am J Ind Med 2017;60:724-33. doi:10.1002/ajim.22736 
10 Palmer KT, D'Angelo S, Syddall H, et al. Dupuytren's contracture and occupational exposure to hand-transmitted vibration. Occup Environ Med 2014;71:241-5. doi:10.1136/oemed-2013-101981

11 Michou L, Lermusiaux J-L, Teyssedou J-P, et al. Genetics of Dupuytren's disease. Jt Bone Spine Rev Rhum 2012;79:7-12. doi:10.1016/j.jbspin.2011.05.027

12 Ball C, Izadi D, Verjee LS, et al. Systematic review of non-surgical treatments for early dupuytren's disease. BMC Musculoskelet Disord 2016;17:345. doi:10.1186/s12891-016$1200-y$ 
Table 1: Multivariate analysis describing associations between occupational exposure and Dupuytren's contracture overall and in each age group

\begin{tabular}{|c|c|c|c|c|c|c|}
\hline & Total & $\begin{array}{c}\text { No surgery } \\
\text { count (\%) }\end{array}$ & $\begin{array}{l}\text { Surgery } \\
\text { count (\%) }\end{array}$ & $\begin{array}{c}\text { Adjusted Odds Ratios (95\% } \\
\text { confidence interval) all } \\
\text { participants* }\end{array}$ & $\begin{array}{c}\text { Adjusted Odds Ratios (95\% } \\
\text { confidence interval) }<60 \\
\text { years subgroup* }\end{array}$ & $\begin{array}{c}\text { Adjusted Odds Ratios (95\% } \\
\text { confidence interval) } \geq 60 \\
\text { years subgroup* }\end{array}$ \\
\hline JEM analysis & 23795 & 23697 & 98 & & 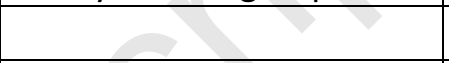 & \\
\hline \multicolumn{7}{|l|}{ JEM exposure } \\
\hline Not exposed (score $=0$ ) & 15884 & $15833(66.8 \%)$ & $51(52.0 \%)$ & ref & ref & Ref \\
\hline Exposed (score $>0$ ) & 7911 & 7864 (33.2\%) & $47(48.0 \%)$ & $1.48(0.96-2.27)$ & $2.08(1.03-4.2)$ & $1.2(0.69-2.08)$ \\
\hline \multicolumn{7}{|l|}{ Age (years) } \\
\hline$<60$ & 16740 & $16703(70.5 \%)$ & $37(37.8 \%)$ & + & P & \\
\hline$\geq 60$ & 7055 & 6994 (29.5\%) & $61(62.2 \%)$ & $3.46(2.26-5.29)$ & & \\
\hline \multicolumn{7}{|l|}{ Sex } \\
\hline Women & 12511 & $12476(52.6 \%)$ & $35(35.7 \%)$ & ref & ref & Ref \\
\hline Men & 11284 & $11221(47.4 \%)$ & $63(64.3 \%)$ & $1.42(0.89-2.26)$ & $1.71(0.81-3.62)$ & $1.23(0.67-2.25)$ \\
\hline \multicolumn{7}{|l|}{ Smoking (Pack-Years) } \\
\hline$=0$ & 10014 & $9979(42.7 \%)$ & $35(35.7 \%)$ & ref & ref & Ref \\
\hline$<30$ & 12198 & $12149(52.0 \%)$ & $49(50.0 \%)$ & $1.12(0.71-1.77)$ & $1.00(0.48-2.05)$ & $1.24(0.69-2.23)$ \\
\hline$\geq 30$ & 1252 & $1238(5.30 \%)$ & $14(14.3 \%)$ & $1.93(0.99-3.78)$ & $2.83(0.96-8.36)$ & $1.65(0.70-3.90)$ \\
\hline \multicolumn{7}{|l|}{ Alcohol (Drinks/day) } \\
\hline$\leq 2$ & 19857 & $19782(84.3 \%)$ & $75(76.5 \%)$ & ref & ref & ref \\
\hline$>2$ & 3716 & $3693(15.7 \%)$ & $23(23.5 \%)$ & $1.22(0.74-2.00)$ & $0.86(0.35-2.14)$ & $1.43(0.79-2.60)$ \\
\hline \multicolumn{7}{|l|}{ Diabetes } \\
\hline No & 22546 & $22460(97.4 \%)$ & $86(91.5 \%)$ & ref & ref & ref \\
\hline Yes & 619 & $611(2.65 \%)$ & $8(8.51 \%)$ & $1.93(0.92-4.08)$ & $2.45(0.57-10.55)$ & $1.86(0.79-4.42)$ \\
\hline Self-reported analysis & 81801 & 81434 & 367 & & & \\
\hline Self-reported exposure & & 1 & & & & \\
\hline No exposure & 55178 & $54950(71.6 \%)$ & $228(66.9 \%)$ & ref & ref & Ref \\
\hline Exposure $>0$ and $<10$ years & 7302 & $7282(9.49 \%)$ & $20(5.87 \%)$ & $0.88(0.56-1.40)$ & $0.81(0.43-1.52)$ & $1.11(0.56-2.19)$ \\
\hline
\end{tabular}




\begin{tabular}{|c|c|c|c|c|c|c|}
\hline Exposure $\geq 10$ and $<20$ years & 4758 & $4733(6.17 \%)$ & $25(7.33 \%)$ & $1.43(0.93-2.21)$ & $1.7(0.98-2.95)$ & $1.17(0.57-2.39)$ \\
\hline Exposure $\geq 20$ years & 9800 & $9732(12.7 \%)$ & $68(19.9 \%)$ & 1.41 (1.06-1.87) & $2.01(1.32-3.04)$ & $1.04(0.70-1.54)$ \\
\hline \multicolumn{7}{|l|}{ Age (years) } \\
\hline$<60$ & 62160 & $61998(76.1 \%)$ & $162(44.1 \%)$ & ref & 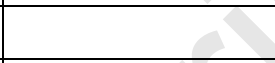 & \\
\hline$\geq 60$ & 19641 & $19436(23.9 \%)$ & $205(55.9 \%)$ & $3.79(3.02-4.76)$ & 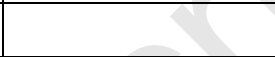 & \\
\hline \multicolumn{7}{|l|}{ Sex } \\
\hline Women & 43065 & $42926(52.7)$ & $139(37.9)$ & ref & ref & ref \\
\hline Men & 38736 & $38508(47.3)$ & $228(62.1)$ & $1.58(1.24-2.00)$ & $1.53(1.08-2.17)$ & $1.61(1.16-2.24)$ \\
\hline \multicolumn{7}{|l|}{ Smoking (Pack-Years) } \\
\hline$=0$ & 35920 & $35780(44.7)$ & $140(39.0)$ & ref & ref & ref \\
\hline$<30$ & 40868 & $40684(50.9)$ & $184(51.3)$ & $1.05(0.83-1.33)$ & $1.09(0.77-1.55)$ & $1.01(0.74-1.38)$ \\
\hline$\geq 30$ & 3528 & 3493 (4.37) & $35(9.75)$ & $1.20(0.78-1.83)$ & $2.6(1.38-4.9)$ & $0.75(0.43-1.34)$ \\
\hline \multicolumn{7}{|l|}{ Alcohol (Drinks/day) } \\
\hline$\leq 2$ & 68350 & $68066(84.7)$ & $284(78.2)$ & ref & ref & ref \\
\hline$>2$ & 12334 & 12255 (15.3) & $79(21.8)$ & $1.13(0.86-1.49)$ & $0.82(0.5-1.34)$ & $1.34(0.95-1.88)$ \\
\hline \multicolumn{7}{|l|}{ Diabetes } \\
\hline No & 78057 & 77727 (97.8) & $330(92.7)$ & ref & ref & ref \\
\hline Yes & 1810 & $1784(2.24)$ & $26(7.30)$ & $2.00(1.30-3.07)$ & 3.19 (1.47-6.94) & $1.75(1.05-2.92)$ \\
\hline
\end{tabular}

* JEM exposure and self-reported exposure are adjusted for sex, smoking, alcohol intake and diabetes 